\title{
Botulinum Toxin Type A and Acute Drug Costs in Migraine with Triptan Overuse
}

\author{
Suzanne N. Christie, Rose Giammarco, Marek Gawel, Gordon Mackie, \\ Jonathan Gladstone, Werner J. Becker
}

\begin{abstract}
Background: Patients with chronic migraine and medication overuse are significant consumers of health care resources. Objective: To determine whether botulinum toxin type A prophylaxis reduces the cost of acute migraine medications in patients with chronic migraine and triptan overuse. Methods: In this multicenter, open-label study, patients with chronic migraine ( $\geq 15$ headache days/month) who were triptan overusers (triptan intake $\geq 10$ days/month for $\geq 3$ months) received botulinum toxin type A (95-130 U) at baseline and month three. Headache (HA) frequency and medication use were assessed with patient diaries, and headache-related disability by means of the MIDAS and Headache Impact Test- 6 questionnaires. Results: Of 53 patients enrolled (mean age \pm standard deviation, 46.5 years $\pm 8.4 ; 47$ [88.7\%] females), 48 (90.6\%) completed the study at month six. Based on headache diaries, significant $(P \leq 0.0002)$ decreases from baseline were observed for days per month with headache/migraine, days with any acute headache medication use, days with triptan use, and triptan doses taken per month. A significant $(P<0.0001)$ increase from baseline in headachefree days per month was also observed. Prescription medication costs for acute headache medications decreased significantly, including significant reductions in triptan costs (mean reduction of -C\$106.32 $\pm 122.87 /$ month during botulinum toxin type A prophylaxis; $\mathrm{P}<0.0001$ ). At baseline, $78 \%$ of patients had severe disability (MIDAS score) and $86.8 \%$ had severe impact due to headache (HIT-6 scores); at month six, this decreased to $60 \%$ and $68 \%$, respectively. Conclusions: Botulinum toxin type A prophylactic therapy markedly decreased costs related to acute headache medication use in patients with chronic migraine and triptan overuse.
\end{abstract}

RÉSUMÉ: Toxine botulique de type A et coût des médicaments utilisés en phase aiguë de la migraine avec surutilisation de triptans. Contexte: Les patients qui souffrent de migraine chronique et qui surutilisent leur médication sont des consommateurs importants de soins de santé. Objectif : Le but de l'étude était de déterminer si la prophylaxie par la toxine botulique de type A (BoNTA) diminue le coût de la médication utilisée pour traiter la migraine aiguë chez les patients qui souffrent de migraine chronique et qui surutilisent les triptans. Méthodes : Au cours de cette étude ouverte, multicentres, les patients atteints de migraine chronique ( $\geq 15$ jours de céphalée par mois) qui surutilisaient des triptans (prise de triptans $\geq 10$ jours par mois pendant $\geq 3$ mois) ont reçu de la toxine botulique de type A (95-130 U) au début de l'étude et 3 mois plus tard. La fréquence des céphalées et l'utilisation de la médication ont été évaluées au moyen de carnets de migraine et l'invalidité due à la céphalée au moyen des tests de migraine MIDAS et HIT-6. Résultats : Quarante-huit $(90,6 \%)$ des 53 patients admis dans l'étude ont complété cette étude de 6 mois (âge moyen 46,5 \pm 8,4 ans ; 47 femmes, soit $88,7 \%)$. Selon les carnets de migraine remplis par les patients, une diminution significative $(\mathrm{p} \leq 0,0002)$ du nombre de jours par mois où la céphalée/la migraine était présente, où une médication contre la céphalée aiguë a été utilisée et où un triptan a été utilisé, ainsi qu'une diminution des doses de triptan ont été observées par rapport au début de l'étude. Une augmentation significative (p $\leq 0,0001)$ du nombre de jours par mois sans céphalée a également été observée. Les coûts des médicaments sous prescription pour les médicaments contre la céphalée aiguë ont diminué significativement, dont une diminution significative des coûts reliés à l'utilisation des triptans (diminution moyenne de $-106,32 \pm 122,87$ \$CA/mois pendant la prophylaxie par BoNTA; $p<0,0001$ ). Au début de l'étude, l'invalidité était sévère chez $78 \%$ des patients (score MIDAS) et 86,8\% avaient un impact sévère dû à la céphalée (score HIT-6) ; après 6 mois, les pourcentages avaient diminué à $60 \%$ et $68 \%$ respectivement. Conclusions : La prophylaxie par la toxine botulique de type A diminue de façon appréciable les coûts associés à l'utilisation de la médication contre la céphalée aiguë chez les patients atteints de migraine chronique qui surutilisent les triptans.

Can. J. Neurol. Sci. 2010; 37: 588-594

Individuals with migraine appear particularly prone to the development of chronic daily headache (HA) [headache on $\geq 15$ days a month] with symptomatic medication overuse ${ }^{1,2}$. In addition to ergotamines and analgesics, frequent triptan use for symptomatic migraine treatment (on ten days a month or more) has also been implicated in the genesis of medication overuse headache ${ }^{3,4}$. Migraine with medication overuse not only results in significant disability for many migraine sufferers ${ }^{5,6}$, it can also lead to considerable expense for the patient and the healthcare system, particularly if the overused medication is a triptan.

Chronic migraine $(\mathrm{CM})$ with medication overuse presents a challenging clinical problem to the physician. It has traditionally been suggested that patients with chronic migraine and medication overuse may be more refractory to conventional prophylactic therapy; however there is recent evidence that such patients may respond to some degree to topiramate

From the Department of Neurology (SNC), University of Ottawa, Ottawa; Department of Neurology (RG), McMaster University, Hamilton; Department of Neurology (MG), University of Toronto, Toronto; Gladstone Headache Clinic (JG), Toronto, Ontario; Department of Neurology (GM), Richmond Hospital, Richmond, British Columbia; Department of Clinical Neurosciences (WJB), University of Calgary, Calgary, Alberta, Canada.

Received January 5, 2010. Final Revisions Submitted March 17, 2010. Correspondence to: Werner J. Becker, Division of Neurology, Foothills Hospital, 1403 29th St NW, Calgary, Alberta, T2N 2T9, Canada. 
prophylaxis $^{7,8}$. There is also evidence that the use of botulinum toxin type A (BoNTA) prophylaxis reduces the number of patients with medication overuse in a chronic migraine patient sample $^{9}$ and reduces the number of days on which acute headache medication is taken compared to placebo ${ }^{10}$.

If migraine prophylaxis with BoNTA has the ability to reduce the frequency of acute headache medication use in patients with chronic migraine and triptan overuse, there is potential for a meaningful reduction in symptomatic medication costs. Our study was designed to demonstrate whether treatment with BoNTA reduced acute (symptomatic) medication cost in patients with chronic migraine and triptan overuse. The primary endpoint was the monthly cost of all acute migraine medications during prophylactic treatment with BoNTA as compared to baseline values before BoNTA treatment was started.

\section{Patients And Methods}

\section{Participant Characteristics}

Patients meeting the inclusion and exclusion criteria were recruited from six neurological headache practices from across Canada. These headache clinics were those of the authors of this paper, and included one in British Columbia, one in Alberta, and four in Ontario.

\section{Inclusion Criteria}

Patients included in this study were men and women aged 18 to 65 years with chronic migraine defined as $\geq 15$ headache days per month; $50 \%$ of which were migraine headache fulfilling the International Classification for Headache Disorders second edition (ICHD-II) criteria $\mathrm{C}$ and $\mathrm{D}$ for 1.1 migraine without aura ${ }^{11}$; stable headache severity and pattern as determined by the investigator. To be eligible for participation, patients also had to fulfill the following criteria: headache data available for at least six months prior to BoNTA administration in the study; triptan overuse as defined by ICHD-II 8.2.2 (triptan intake $\geq 10$ days per month on a regular basis for $\geq 3$ months) ${ }^{11}$; no prophylactic migraine medication for $\geq 2$ months prior to screening phase; and ability to understand the study requirements, including completing questionnaires and maintaining a patient diary. Women of childbearing potential were required to have a negative urine pregnancy test.

\section{Exclusion Criteria}

Patients were excluded from the study for the following reasons: $\geq 3$ previous prophylactic medications failed because of lack of efficacy (patients must have received a prophylactic treatment for at least two months for the medication to be considered a failure); contraindication to the use of triptans or analgesics; any medical condition that might increase the risk of exposure to BoNTA; any disease that might interfere with neuromuscular function; profound atrophy or excessive weakness of the muscles to be injected; skin problems or infection at any of the injection sites; previous use of BoNT therapy or sensitivity to any component of BoNTA; evidence of alcohol/drug abuse; and a clinically significant psychiatric disorder or a Beck Depression Inventory score of $>24$ at the time of consent. Women who were pregnant, planning to become pregnant or breast-feeding were also excluded.

\section{Study Design: Treatment Schedule and Protocol}

In this multicenter, open-label study, patients with chronic migraine complicated by triptan overuse received 95 to 130 units (U) of BoNTA using the follow-the-pain approach as described by Blumenfeld et $\mathrm{al}^{12}$. The formulation of BoNTA used was manufactured by Allergan Inc. (Irvine, CA, USA). The study duration was approximately 7.5 months, which included a 1.5month screening phase and a six-month treatment phase (Figure 1). The screening phase included a one month baseline period. Patients were screened for study inclusion and exclusion criteria at month -1.5; eligible patients received a BoNTA injection at the beginning of the treatment phase after completion of data collection for a one month baseline period, and a second injection three months later. Headache diaries were dispensed at month -1.5 through month 5 and collected at month -1 through month 6. Migraine Disability Assessment (MIDAS) and a study questionnaire which assessed the effect of migraine on factors related to patient health-related quality of life (HRQoL) were assessed at baseline and at months three and six. Headache Impact Test (HIT-6) was assessed at baseline and monthly for months one through six.

Use of any concomitant medication or treatment was documented; efforts were made to keep all concomitant therapies constant throughout the study. Patients were prohibited from taking the following medications during the study period: prophylactic migraine drugs (eg, beta blockers, calcium channel blockers, anticonvulsants, and antidepressants), selective serotonin reuptake inhibitors, and agents that might interfere with neuromuscular function (eg, aminoglycoside antibiotics, curare-like agents).

All patients signed informed consent, and the study complied with recognized Good Clinical Practice guidelines and applicable regulatory requirements, ie, compliance with the ethical principles described in the current revision of the Declaration of Helsinki. The study was also carried out according to Canadian legal and regulatory requirements and received ethical approval at all participating centers.

\section{Efficacy Measures}

\section{Primary and Secondary End Points}

The primary end point was the monthly cost of all acute migraine treatment medications, comparing the period with BoNTA prophylactic treatment to baseline values for the month before BoNTA treatment was started. Secondary end points included the following: cost of triptan therapy; number of headache-free days per month; mean change from baseline in the number of headache and migraine days per month; intensity of headaches; headache-related disability; and acute medication use. Headache diaries assessed headache and migraine days, headache-free days, and days on acute headache medication including triptans, triptan doses, and cost of use for six months.

A study questionnaire was used to evaluate factors related to HRQoL. This questionnaire evaluated how much the patient's migraine pain interfered with mood, ability to walk or move about, sleep, normal work, recreational activities and enjoyment of life during the past month on a five point scale ranging through 0 (not at all), 1 (a little bit), 2 (moderately), 3 (quite a bit), and 4 (extremely). The degree to which daily activities were 
affected by migraine symptoms over the past three months was rated by the patient on the same scale. The MIDAS and HIT-6 were used to evaluate headache-related disability.

The triptan costs used in this study represent average Canadian costs, and were obtained through information received from five Canadian pharmacies. Costs were calculated for each patient individually based upon the type of triptan taken by the patient.

\section{Safety Assessments}

Throughout the study, patients were monitored for signs and symptoms of adverse events (AEs). The study investigators were required to document all AEs, including serious and unexpected AEs. Documentation included description of the AE, onset date, duration, severity, and course of action taken, if any.

\section{Statistical Analyses}

The sample size was chosen in order to detect a $30 \%$ reduction in the total monthly cost of acute medications used for the treatment of migraine, comparing the final month of the study (the third month after the second BoNTA injection) to the baseline month before the first injection of BoNTA. Efficacy and safety analyses were conducted on an intent-to-treat basis, with no imputation for missing values. Subjects who met the study criteria and received BoNTA were included in the analysis. Summary tables were used to present patient population characteristics at baseline. Continuous data were summarized using descriptive statistics; categorical data were summarized in frequency tables. Continuous variables were compared before and after study medication administration using analysis of variance (ANOVA). Mean ( \pm standard deviation $[S D]$ ) change from baseline data was analyzed using the $t$ test or Wilcoxon signed rank test, depending on the normality of data distribution.

\section{RESULTS}

Of 53 patients enrolled, $48(90.6 \%)$ completed the study at month six. The primary reason for discontinuation was lack of efficacy (2), lost to follow-up (2), and other (1). Mean total BoNTA dose received at the beginning of month one (first injection) and at the beginning of month four (second injection) was $105.8 \pm 13.6 \mathrm{U}$ and $106.9 \pm 14.2 \mathrm{U}$, respectively. Patient
Table 1: Patient demographics and baseline characteristics

\begin{tabular}{|c|c|}
\hline \multicolumn{2}{|l|}{ Open-label BoNTA (N=53) } \\
\hline \multicolumn{2}{|l|}{ Sex, n (\%) } \\
\hline Male & $6(11.3)$ \\
\hline Female & $47(88.7)$ \\
\hline Age $(y)$, mean \pm SD & $46.5 \pm 8.4$ \\
\hline \multicolumn{2}{|l|}{ Race, n (\%) } \\
\hline White & $48(90.6)$ \\
\hline Black & $1(1.9)$ \\
\hline Asian & $3(5.7)$ \\
\hline Other & $1(1.9)$ \\
\hline \multicolumn{2}{|l|}{ MIDAS score, n (\%) } \\
\hline Little or no disability $(0-5)$ & $5(10)$ \\
\hline Mild disability (6-10) & 0 \\
\hline Moderate disability (11-20) & $6(12)$ \\
\hline Severe disability $(21+)$ & $39(78)$ \\
\hline \multicolumn{2}{|l|}{ HIT-6 score } \\
\hline$\leq 49$ (little or no impact) & 0 \\
\hline 50 to 55 (some impact) & $2(3.8)$ \\
\hline 56 to 59 (substantial impact) & $5(9.4)$ \\
\hline 60 or more (severe impact) & $46(86.8)$ \\
\hline
\end{tabular}

demographics and baseline clinical characteristics are presented in Table 1.

\section{Primary Outcome Measure: Cost of Acute Migraine Prescription Medications}

The non-triptan acute headache medication costs were relatively minimal and averaged only $C \$ 7.39 \pm 9.95$ during the baseline month. On average, there was no change in monthly non-triptan medication costs during BoNTA six month treatment period. As non-triptan HA medications were not a significant contributor to medication costs $(<3 \%)$ and were not affected by BoNTA treatment, triptan costs were used in the main data analysis, and are shown in (Table 2).

At baseline mean $( \pm \mathrm{SD})$ mean triptan costs were C $\$ 291.68 \pm$ 148.13 per month; during month six they were $\mathrm{C} \$ 181.97 \pm$ 106.20 , a decrease of approximately $C \$ 110(P<0.0001, t$ test $)$ per month. The average triptan savings per month over the six month

Table 2: Monthly cost reduction from baseline of triptan medication in patients with chronic migraine treated with botulinum toxin type A

\begin{tabular}{lll}
\hline & Cost Reduction* & $P$-value \\
\hline Triptans & $\$ 291.68 \pm 148.13$ (baseline) & \\
\hline Change from baseline to month 1 & $-\$ 87.47 \pm 115.72$ & $P<0.0001^{\dagger}$ \\
Change from baseline to month 2 & $-\$ 109.58 \pm 145.52$ & $P<0.0001^{\dagger}$ \\
Change from baseline to month 3 & $-\$ 95.33 \pm 143.84$ & $P<0.0001^{\dagger}$ \\
Change from baseline to month 4 & $-\$ 112.50 \pm 124.69$ & $P<0.0001^{\dagger}$ \\
Change from baseline to month 5 & $-\$ 124.42 \pm 144.57$ & $P<0.0001^{\dagger}$ \\
Change from baseline to month 6 & $-\$ 110.26 \pm 143.41$ & $P<0.0001^{\dagger}$ \\
Average triptan savings/month & $-\$ 106.32 \pm 122.87$ & $P<0.0001^{\dagger}$ \\
\hline
\end{tabular}

$*$ Canadian $\$ ; \dagger t$ test. Values are expressed as mean \pm SD. 


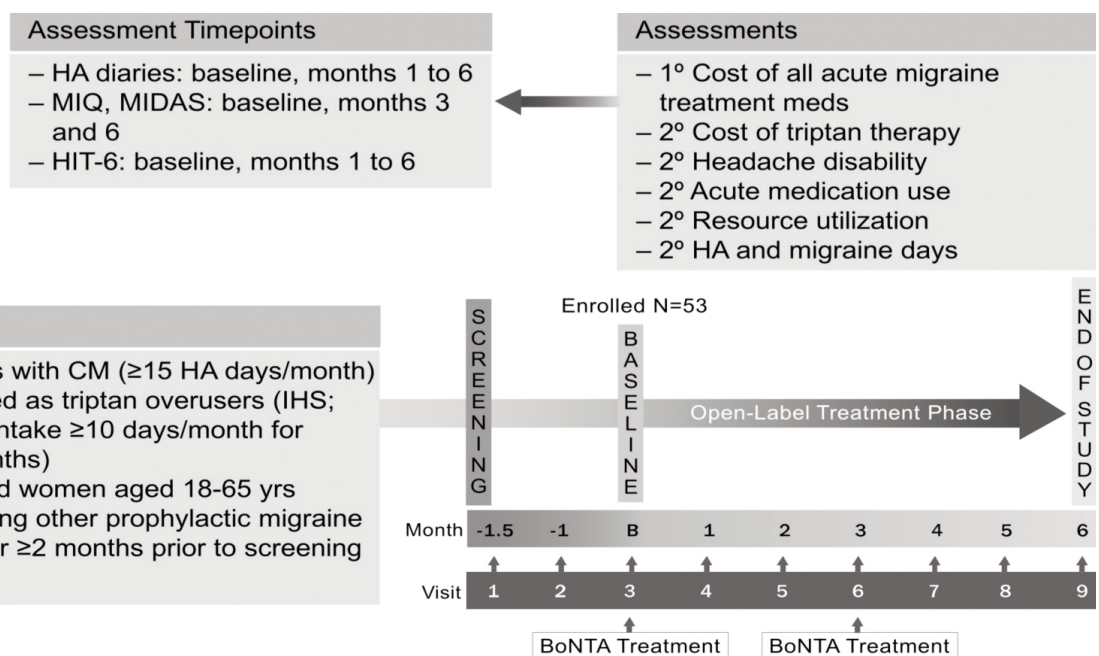

Figure 1: Trial design. HA: headache. MIQ: migraine impact questionnaire, a study questionnaire which assessed the effect of migraine on factors related to patient health-related quality of life. MIDAS: migraine disability assessment score. HIT-6: headache impact test. CM: chronic migraine.

study period was $\mathrm{C} \$ 106.32 \pm 122.87(P<0.0001, t$ test $)$. Patient satisfaction with cost of migraine medications increased significantly $(P \leq 0.0184)$.

\section{Secondary Outcome Measures}

\section{Days on Acute Headache Medication, Days on Triptans, and Triptan Doses}

At baseline, mean number of days per month on which patients took any acute HA medication, mean number of days per month with triptan use, and mean number of triptan doses taken per month were $20.04 \pm 5.94,15.99 \pm 5.69$, and $21.28 \pm 10.02$, respectively. There was a significant average monthly decrease from baseline in days on HA medication (-5.26 \pm 5.27 , $P<0.0001, t$ test $)$, days on triptans $(-5.15 \pm 5.13, P<0.0001, t$ test), and triptan doses $(-7.23 \pm 9.15, P<0.0001, t$ test) (Figure 2$)$. The mean percent reduction from baseline to month six in days on HA medication, days on triptans, and triptan doses was also significant: $-28.3 \% \pm 28.3,-30.0 \% \pm 32.8$, and $-29.1 \% \pm 39.5$, respectively $(P<0.0001, t$ test). The percentage of patients with at least a $50 \%$ decrease from baseline in days on HA medication, days on triptan, and triptan doses were $20.8 \%, 24.5 \%, 30.2 \%$, respectively.

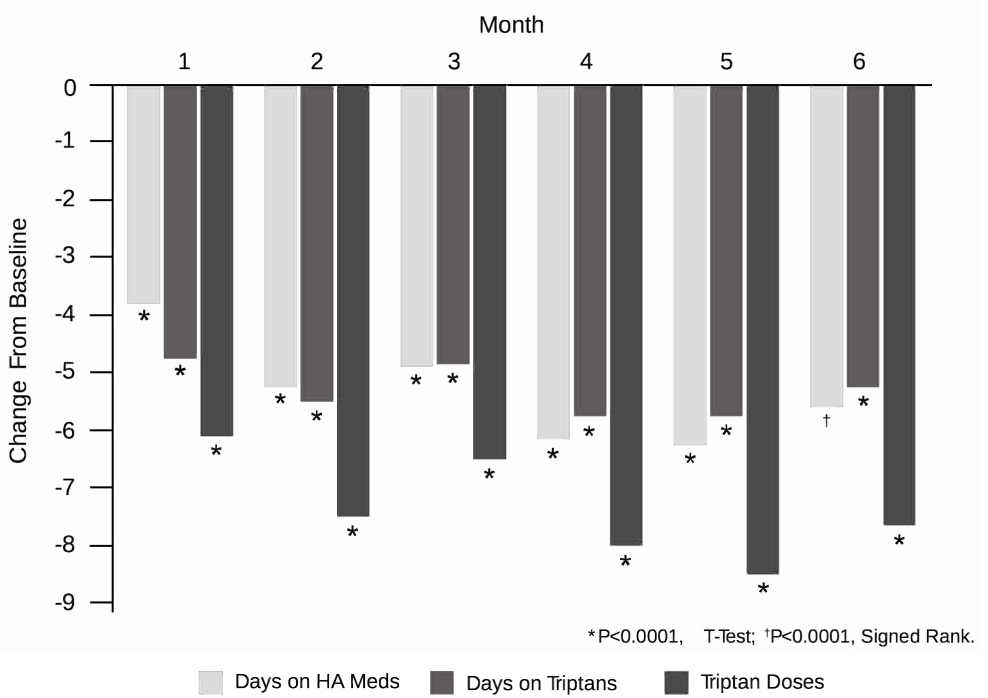

Figure 2: Change from baseline in days on HA meds, days on Triptans, and Triptan doses. Changes in acute headache medication use are shown for each month on BoNTA treatment as compared to baseline. For each month, the left bar indicates the mean reduction in the number of days per month that any symptomatic medication was taken, the middle bar indicates the mean reduction in days per month that a triptan was taken, and the right bar shows the mean reduction in the number of triptan doses taken per month. 


\section{Headache and Migraine Days}

At baseline, mean HA days and migraine days were $20.87 \pm$ 5.60 and $13.21 \pm 6.62$, respectively. Average days with HA and migraine per month decreased significantly $(-5.03 \pm 5.13$ and $3.97 \pm 5.68, P<0.0001, t$ test) (Figure 3$)$. The mean percent reduction from baseline to month six in days with HA and migraine was also significant $(-27.7 \% \pm 29.1, P<0.0001, t$ test, and $-9.3 \% \pm 102.3, P=0.0026$, signed rank, respectively). The percentage of patients with at least a $50 \%$ decrease from baseline in HA days and migraine days were $20.8 \%$ and $27.5 \%$, respectively. In addition, there was a significant $(P<0.0001, t$ test) average monthly increase of $5.03 \pm 5.13$ in mean HA-free days.

\section{Headache severity}

Average headache severity as reported by the study subjects was $2.00 \pm 0.32$ (on a scale of $0-4$, with 4 indicating the most severe level) during the baseline month, and $2.00 \pm 0.41$ during month six. There was also no change in the average headache severity at the time when the patients took their triptan medications $(2.26 \pm 0.42$ during the baseline month, and $2.18 \pm$ 0.42 during month six).

\section{Disability measurements and HRQoL parameters}

Mean MIDAS scores decreased from $61.96 \pm 48.39(\mathrm{~N}=50)$ at baseline to $34.64 \pm 33.52(\mathrm{~N}=45)(p<0.00001)$ at 6 months, and mean HIT-6 scores decreased from $66.09 \pm 5.00(\mathrm{~N}=53)$ at baseline to $61.02 \pm 7.63)(\mathrm{N}=50)(p<0.0001)$ at six months. At baseline, MIDAS scores indicated that $78 \%$ had severe disability; at month six, this decreased to $60 \%$. At the end of study (month six), approximately half of the patients $(44.2 \%$ ) reported $\geq 50 \%$ improvement in their MIDAS scores and more than half $(67.4 \%)$ reported $\geq 25 \%$ improvement. Almost onethird $(30.2 \%)$ of patients reported a $\geq 75 \%$ improvement in their MIDAS score at month six. Headache Impact Test-6 scores indicated that $86.8 \%$ had severe impact due to HA at baseline; this decreased to $68 \%$ at month six.

The study questionnaire indicated a significant improvement ( $t$ test or signed rank as noted in Table 3 ) in days worked with migraine symptoms; daily activities affected by migraine symptoms; and interference of migraine pain with activities such as mood, ability to walk or move about, sleep, normal work, recreational activities, and enjoyment of life.

\section{Safety and Adverse Events}

Twelve patients $(22.6 \%)$ reported 15 transient and mild-tomoderate treatment-related AEs; 16 patients (30.2\%) reported 22 AEs possibly related to study treatment. There were no reports of serious AEs. The most frequent treatment-related AEs were ptosis (five patients) and neck muscle weakness (two patients).

\section{Discussion}

In our patient sample with chronic migraine and triptan overuse, the total monthly cost of symptomatic (acute) migraine medications was reduced during BoNTA prophylactic therapy as compared to baseline values measured before BoNTA treatment was started. Monthly headache days, days with migraine, days with any acute headache medication use, days with triptan use, and the number of triptan doses each taken each month were all reduced for each month after the onset of BoNTA treatment as compared to baseline. Multiple factors related to HRQoL as measured by the study questionnaire also improved, and headache-related disability as measured by the MIDAS and the HIT-6 was reduced.

Our results are consistent with findings from double blind placebo-controlled trials which have also reported a decrease in acute headache medication use in patients with chronic daily headache during BoNTA prophylaxis ${ }^{9,10}$. In those studies, this reduction in acute medication use was most marked in patients with acute medication overuse and who were not taking other

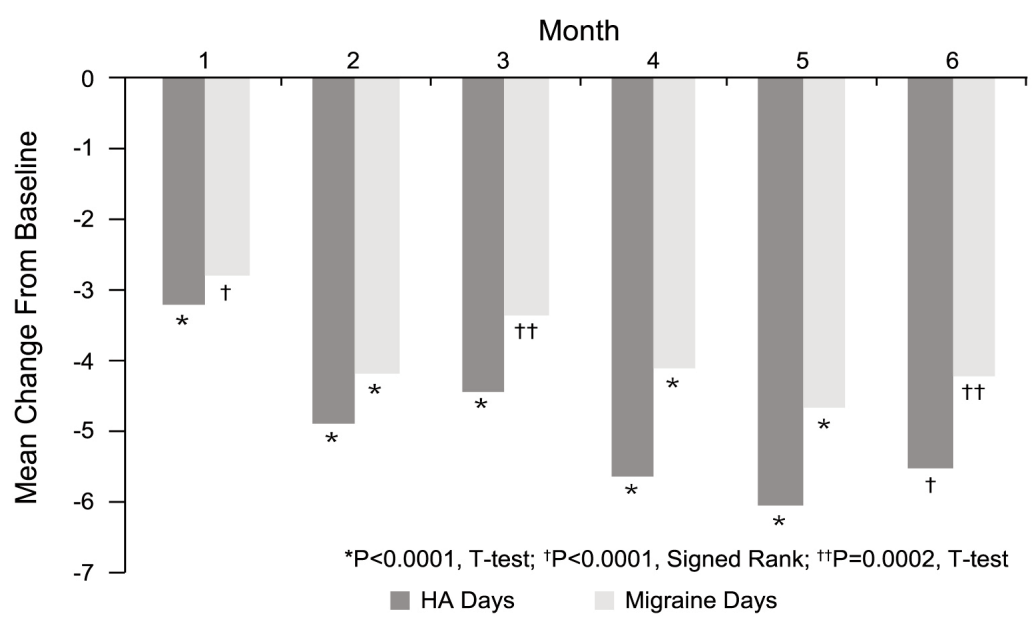

Figure 3: Significant decrease in HA and migraine days after BoNTA prophylactic treatment in patients with CM. Changes in mean headache and migraine days are shown for each month on BoNTA treatment as compared to baseline. For each month, the left bar shows the reduction in headache days, and the right bar shows the reduction in migraine days. 
Table 3: Study questionnaire results indicate HRQoL improvement during BoNTA prophylactic treatment in patients with $\mathrm{CM}$

\begin{tabular}{|c|c|c|c|}
\hline & & \multicolumn{2}{|c|}{ Change From Baseline } \\
\hline & Baseline & $\begin{array}{l}\text { Month } 3 \\
(P \text { value }) \\
\end{array}$ & $\begin{array}{l}\text { Month } 6 \\
(P \text { value }) \\
\end{array}$ \\
\hline $\begin{array}{l}\text { Days worked with migraine symptoms (in } 3 \text { month } \\
\text { period) }\end{array}$ & $32.20 \pm 21.74$ & $\begin{array}{c}-11.00 \pm 19.89 \\
\left(0.0005^{*}\right)\end{array}$ & $\begin{array}{l}-13.51 \pm 20.28 \\
(<0.0001 *)\end{array}$ \\
\hline Daily activities affected by migraine symptoms** & $2.85 \pm 0.77$ & $\begin{array}{l}-0.62 \pm 0.82 \\
\left(<0.0001^{\dagger}\right)\end{array}$ & $\begin{array}{l}-0.76 \pm 0.90 \\
\left(<0.0001^{\dagger}\right)\end{array}$ \\
\hline \multicolumn{4}{|c|}{ Interference of migraine pain on the following: $* * *$} \\
\hline Mood & $2.34 \pm 1.00$ & $\begin{array}{l}-0.52 \pm 1.08 \\
\left(<0.0001^{\dagger}\right)\end{array}$ & $\begin{array}{l}-0.57 \pm 1.14 \\
\left(<0.0001^{\dagger}\right)\end{array}$ \\
\hline Ability to walk/move about & $1.72 \pm 1.08$ & $\begin{array}{c}-0.35 \pm 0.91 \\
\left(0.0073^{\dagger}\right)\end{array}$ & $\begin{array}{l}-0.43 \pm 1.26 \\
\left(0.0068^{\dagger}\right)\end{array}$ \\
\hline Sleep & $2.23 \pm 1.12$ & $\begin{array}{c}-0.56 \pm 1.05 \\
\left(0.0005^{\dagger}\right)\end{array}$ & $\begin{array}{l}-0.67 \pm 1.12 \\
\left(<0.0001^{\dagger}\right)\end{array}$ \\
\hline Normal work & $2.45 \pm 1.10$ & $\begin{array}{c}-0.53 \pm 1.08 \\
\left(0.0008^{\dagger}\right)\end{array}$ & $\begin{array}{l}-0.71 \pm 1.27 \\
\left(<0.0001^{\dagger}\right) \\
\end{array}$ \\
\hline Recreational activities & $2.49 \pm 1.07$ & $\begin{array}{l}-0.78 \pm 1.17 \\
\left(<0.0001^{\dagger}\right)\end{array}$ & $\begin{array}{c}-0.67 \pm 1.42 \\
\left(0.0013^{\dagger}\right)\end{array}$ \\
\hline Enjoyment of life & $2.66 \pm 1.07$ & $\begin{array}{l}-0.76 \pm 1.14 \\
\left(<0.0001^{\dagger}\right)\end{array}$ & $\begin{array}{l}-0.67 \pm 1.43 \\
\left(0.0013^{\dagger}\right)\end{array}$ \\
\hline
\end{tabular}

Values are expressed as mean \pm SD. $*$ T-test, $\dagger$ Signed rank, $* *$ Over a three month time period. Range of scores $0=$ not at all, to $4=$ extremely. $* * *$ Over a one month time period. Range of scores $0=$ not at all, to $4=$ extremely.

prophylactic treatments ${ }^{10}$. In our study, all patients were triptan overusers and none were taking other prophylactic medications during the study. This may have accounted for the relatively dramatic reductions in acute medication use seen in our patient sample. As triptans are expensive medications, this resulted in significant cost savings in terms of symptomatic medication costs.

We found average per patient triptan cost savings per month following BoNTA prophylaxis treatment of C\$106.32 \pm 122.87 providing a total six-month savings of approximately C $\$ 638$ per patient. The findings of our study were similar to those observed in a retrospective study of a claims database by Silberstein et al ${ }^{13}$ that analyzed the effect of preventive therapy on resource utilization, including triptans. In the Silberstein et al ${ }^{13}$ retrospective study, triptan savings per patient per month following migraine prophylaxis in the group with the highest level of triptan use were $\$ 88.53$, providing a total cost savings of $\$ 531.18$ for the first six months. In the same group, over the second six-month period following initial prophylactic therapy, the cost savings per patient per month had increased to $\$ 131.68$, with a total 6-month savings of $\$ 790.07$. It was also noted that those with the highest level of triptan use ( $>10$ units/month) had a substantially higher cost saving compared with the next highest user group (8-10 units/month).

Another 12-month retrospective study of an administrative database by Etemad et $\mathrm{al}^{14}$ also observed an acute medication cost reduction in association with drug prophylaxis in patients with moderate-to-severe migraine, with a reduction in total migraine cost of $\$ 560$ per patient per year from 1998 to 2001 . Evidence from all three studies suggests that prophylactic treatment provides acute medication cost-saving benefits in high utilizers of acute migraine therapy.

The mechanism whereby BoNTA might reduce migraine frequency and / or intensity to result in less acute medication need is not clear. Nociception is mediated by the release of neuropeptides by sensory neurons including substance $\mathrm{P}$, calcitonin gene-related peptide (CGRP), and glutamate. The release of substance $\mathrm{P}$ and CGRP is postulated to contribute to activation and sensitization of peripheral afferents during migraine attacks ${ }^{15-17}$. There is evidence that BoNTA may inhibit neurogenic inflammation by blocking release of certain neurotransmitters from peripheral terminals of primary afferents (nociceptors), in effect inhibiting peripheral sensitization ${ }^{18,19}$. Reduction of sensitization in peripheral neurons may indirectly affect central sensitization by reducing incoming stimuli and the release of neuroinflammatory mediators.

Limitations of our study include the lack of a placebo arm and the open-label design. All outcome measures during treatment with BoNTA were compared to baseline values in the same subject, and a placebo effect may have contributed to our findings. Another limitation is that our study excluded patients who had failed three or more prophylactics in the past because of lack of efficacy. This was done to exclude patients who in the past had shown evidence of being completely unresponsive to pharmacological preventative interventions. However, this exclusion does limit the generalizability of our findings with 
regard to patients with chronic migraine and triptan overuse. Strengths of our study include the use of diary data to record outcome measures. In addition, our study closely mimicked the conditions under which BoNTA is used in clinical practice, where patients know that they are receiving BoNTA. It should therefore reflect closely the results which might be expected when BoNTA prophylaxis is provided to patients with chronic migraine and triptan overuse in routine clinical practice with the limitation noted above. It should also be noted that several different formulations of botulinum toxin type A are in clinical use, and these differ in structure and molecular weight. The formulation of BoNTA used in our study was manufactured by Allergan Inc. (Irvine, CA, USA), and our results may not apply to other botulinum toxin type A formulations.

\section{Conclusions}

In summary, we found substantial reductions in the cost of acute migraine medications taken by patients with chronic migraine and triptan overuse when BoNTA prophylaxis was used. Over six months of BoNTA use, the savings due to reduction in triptan use averaged over $\mathrm{C} \$ 106$ per month per patient. At the same time, patients demonstrated a significant improvement in health-related quality of life parameters, and a significant reduction in headache-related disability as measured by the MIDAS and the HIT-6. These savings in acute medication costs have the potential to significantly offset the cost of BoNTA prophylaxis.

\section{ACKNOWLEDGMent AND CONFLICT OF INTEREST}

This study was supported by Allergan, Inc. Drs. Becker, Christie, Giammarco, Gawel and Gladstone have served on Allergan Inc. medical advisory boards. Dr. Gladstone owns Allergan stock.

\section{REFERENCES}

1. Wilkinson SM, Becker WJ, Heine JA. Opiate use to control bowel motility may induce chronic daily headache in patients with migraine. Headache. 2001 Mar;41(3):303-9.

2. Bahra A, Walsh M, Menon S, Goadsby PJ. Does chronic daily headache arise de novo in association with regular use of analgesics? Headache. 2003 Mar;43(3):179-90.

3. Limmroth V, Katsarava Z, Fritsche G, Przywara S, Diener HC. Features of medication overuse headache following overuse of different acute headache drugs. Neurology. 2002 Oct 8;59(7): $1011-4$.
4. Katsarava Z, Fritsche G, Muessig M, Diener HC, Limmroth V. Clinical features of withdrawal headache following overuse of triptans and other headache drugs. Neurology. 2001 Nov 13;57 (9):1694-8.

5. Andrasik F, Grazzi L, Usai S, D'Amico D, Kass S, Bussone G. Disability in chronic migraine with medication overuse: treatment effects at 3 years. Headache. 2007;47:1277-81

6. Zeeberg P, Olesen J, Jensen R. Probable medication-overuse headache: the effect of a 2-month drug-free period. Neurology. 2006 Jun 27;66(12):1894-8.

7. Diener HC, Dodick DW, Goadsby PJ, Bigal ME, Bussone G, Silberstein SD, et al. Utility of topiramate for the treatment of patients with chronic migraine in the presence or absence of acute medication overuse. Cephalalgia. 2009 Oct;29(10): $1021-7$.

8. Diener HC, Bussone G, Van Oene JC, Lahaye M, Schwalen S, Goadsby PJ; TOPMAT-MIG-201(TOP-CHROME) Study Group. Topiramate reduces headache days in chronic migraine: a randomized, double-blind, placebo-controlled study. Cephalalgia. 2007 Jul;27(7):814-23.

9. Silberstein SD, Stark SR, Lucas SM, Christie SN, Degryse RE, Turkel CC. Botulinum toxin type A for the prophylactic treatment of chronic daily headache: a randomized, doubleblind, placebo-controlled trial. Mayo Clin Proc. 2005;80(9): 1126-37.

10. Dodick DW, Mauskop A, Elkind AH, DeGryse R, Brin MF, Silberstein SD. Botulinum toxin type A for the prophylaxis of chronic daily headache: subgroup analysis of patients not receiving other prophylactic medications: a randomized doubleblind, placebo-controlled study. Headache. 2005;45(4):315-24.

11. Headache Classification Subcommittee of the International Headache Society. The International Classification of Headache Disorders: 2nd ed. Cephalalgia. 2004;24 Suppl 1:1-160.

12. Blumenfeld AM, Binder W, Silberstein SD, Blitzer A. Procedures for administering botulinum toxin type A for migraine and tension-type headache. Headache. 2003;43(8):884-91.

13. Silberstein SD, Winner PK, Chmiel JJ. Migraine preventive medication reduces resource utilization. Headache. 2003;43(3): 171-8.

14. Etemad LR, Yang W, Globe D, Barlev A, Johnson KA. Costs and utilization of triptan users who receive drug prophylaxis for migraine versus triptan users who do not receive drug prophylaxis. J Manag Care Pharm. 2005;11(2):137-44.

15. Dodick D, Silberstein S. Central sensitization theory of migraine: clinical implications. Headache. 2006;46 Suppl 4:S182-S91.

16. Durham PL. Calcitonin gene-related peptide (CGRP) and migraine. Headache. 2006;46 Suppl 1:S3-8.

17. Goadsby PJ. Migraine pathophysiology. Headache. 2005;45 Suppl 1:S14-S24.

18. Aoki KR. Evidence for antinociceptive activity of botulinum toxin type A in pain management. Headache. 2003;43(Suppl 1):9-15.

19. Aoki KR. Review of a proposed mechanism for the antinociceptive action of botulinum toxin type A. Neurotoxicology. 2005;26(5): 785-93. 